\title{
A Review of Cervical Cancer in South Africa: Previous, Current and Future
}

\section{Jordaan $\mathbf{S}^{1 *}$, Michelow $\mathbf{P}^{2}$, Richter $\mathbf{K}^{3}$, Simoens $\mathbf{C}^{4}$ and Bogers $\mathrm{J}^{4}$}

${ }^{1}$ Cytology Department, National Health Laboratory Services (NHLS), Johannesburg, South Africa

${ }^{2}$ NHLS and Department of Anatomical Pathology, University of the Witwatersrand, Johannesburg, South Africa

${ }^{3} \mathrm{NHLS}$ Virology Department and Department of Virology, University of Pretoria, South Africa

${ }^{4}$ Department of Cell Biology and Histology, University of Antwerpen, Belgium

\begin{abstract}
Cervical cancer is the second most common cancer in South African women. Opportunistic screening for cervical cancer has been available for the last five decades. In 2000, the South African Department of Health launched a national cervical screening programme. However, this has not been fully implemented. South Africa has the largest expanding HIV burden in the world and it is estimated that 5.7 million South Africans are currently living with HIVIAIDS, of whom $60 \%$ are women. The high prevalence of HIV complicates the situation as HIV-infected women have greater rates of pre-invasive and invasive cervical cancer rates whereas HPV infection promotes the acquisition of HIV. In April 2011 the South African government launched the HIV Counseling and Testing (HCT) campaign, a new national drive to encourage people to know their HIV status and access counseling and treatment including cervical screening. In April 2014 the South African National Department of Health implemented a school-based HPV vaccination program for all girls 9 years and older, in grade 4. The rollout targeted 450000 girls in 17000 public schools. However, the reduction of cervical cancer and its precursor lesions due to HPV vaccination will only be realized in the coming decades. Thus screening for, and management of both pre-invasive and invasive cervical cancer needs to be enhanced. The South African National Department of Health will soon announce and implement a new cervical cancer control policy. This review discusses the history of cervical cancer in South Africa, current prevention strategies and suggestions for an improved cervical screening programme.
\end{abstract}

Keywords: South Africa; Cervical cancer; Cervical screening programmes; HIV/AIDS; HPV vaccination

\section{Introduction}

Cervical cancer remains the second most common cancer diagnosed in women in South Africa with an estimated 7,735 new cases in 2012 and 4,248 women dying from the disease [1]. The very high incidence of cervical cancer is particularly tragic in an era where advances in medical science have proven cervical cancer as a potentially preventable disease. Although cancer kills more people globally than HIV/AIDS, tuberculosis and malaria, in most developed economies cervical cancer has become very uncommon due to successful screening and other preventive strategies [2]. The South African Government spends \$13.3 billion each year on their health service, one of the biggest expenditures in the developing world, yet health care monitor groups like the Health Consumer Powerhouse Ltd (HCP) consistently rate South Africa's public health sector among the worst in the world [3]. Apart from a chronic shortage of qualified doctors, nurses and other healthcare workers, poor management, a lack of much needed medicines as well as essential medical equipment, there is additionally a high burden of infectious disease in South Africa.

Sexually transmitted diseases (STIs) are epidemic in South Africa [4]. The South African Demographic Health Survey of 1997 reported that $12 \%$ of male adults reported symptoms suggestive of an STI. Hundreds of thousands of men from rural areas of South Africa and neighboring countries came to seek work in the gold mines since the beginning of the $20^{\text {th }}$ century. Today, Southern Africa has serious interrelated epidemics of gonorrhea, chlamydia, tuberculosis, human papillomavirus (HPV) and HIV infection. The economic and political migrant labor system provided the foundation for the epidemics seen in Southern Africa today [5]. For example, parts of Botswana have higher syphilis and HIV seroprevalence (67\% and $30 \%$, respectively) than South Africa (12-25\% and 18\%, respectively).

\section{HPV in South Africa}

Various studies have shown that the prevalence of HPV infection in Southern Africa varies per province or district; age group, gender, immunocompetence, e.g. HIV status, collection method and assays used [6-8]. The first study in South Africa to determine the prevalence of HPV was undertaken from March 2004 to May 2007 in Kwazulu Natal [6]. Sexually active HIV-negative women aged 14-30 years were enrolled. Blood and cervicovaginal lavage (CVL) samples were collected from all 224 enrolled women. HPV prevalence was $76.3 \%$ $(171 / 224)$ overall and $70.5 \%$ from women in a rural setting. Among women under 18 years of age, 54.1\% (20/37) had multiple concurrent HPV genotypes detected, whilst prevalence of multiple concurrent infections among women $>18$ years old was $77.4 \%$. The prevalence of high-risk genotypes in this study was $54.5 \%$. HPV prevalence was high both among women $<18$ years $(70.3 \%)$ and $>18$ years $(77.5 \%)$ old $[7,8]$ The overall HPV prevalence of $76.3 \%$ in this study is almost 3-4 folds higher than other reported estimates, demonstrating the high burden amongst both urban and rural women in Kwazulu Natal [8]. The proportion of women infected with the high-risk vaccine genotypes (HPV16 and/or 18) was 21\% (47/224). Similar HPV prevalences were reported from a 2013 study of 1472 women from the Gauteng province attending five urban and peri-urban public health sector clinics. In this population the prevalence of HPV DNA was $74.6 \%$ with high risk HPV (hrHPV) DNA in 54.3\% [9]. HPV type 16 and/or 18 was found in $19.5 \%$ of women.

A large cohort study ( $\mathrm{N}=9429)$ describing the prevalence and distribution of HPV genotypes among women in Cape Town (2014), showed a much lower overall prevalence of HPV DNA of $25.4 \%$ (2389/9429). One or more high-risk HPV genotypes were present in

*Corresponding author: Suzette Jordaan, Cytology department, National Health Laboratory Services (NHLS), Johannesburg, South Africa, Tel: 2711386 6000 E-mail: suzette.jordaan@nhls.ac.za

Received December 16, 2016; Accepted December 22, 2016; Published December 30, 2016

Citation: Jordaan S, Michelow P, Richter K, Simoens C, Bogers J (2016) A Review of Cervical Cancer in South Africa: Previous, Current and Future. Health Care Current Reviews 4: 180. doi: 10.4172/2375-4273.1000180

Copyright: (c) 2016 Jordaan S, et al. This is an open-access article distributed under the terms of the Creative Commons Attribution License, which permits unrestricted use, distribution, and reproduction in any medium, provided the original author and source are credited. 
$78.5 \%(1848 / 2354)$ of the HPV positive women tested which is an overall hrHPV prevalence of $19.6 \%$ (1848/9429), This is considerably lower than that reported in the Kwazulu Natal and Gauteng study [10]. In subSaharan Africa, invasive cervical cancer (ICC) incidence and mortality are among the highest in the world. A cross-sectional epidemiological study assessed human papillomavirus (HPV) prevalence and type distribution in women with ICC in Ghana, Nigeria, and South Africa. Between October 2007 and March 2010, cervical specimens from 659 women were collected (167 in Ghana, 192 in Nigeria and 300 in South Africa); 570 cases were histologically confirmed as ICC. The tumor type was identified in 551/570 women with ICC; squamous cell carcinoma was observed in $476 / 570(83.5 \%)$ cases. The HPV-positivity rate in ICC cases was $90.4 \%(515 / 570)$. In ICC cases with single HPV infection $(447 / 515$ [86.8\%]), the most commonly detected HPV types were HPV 16 (51.2\%), HPV18 (17.2\%), HPV35 (8.7\%), HPV45 (7.4\%), HPV33 (4.0\%) and HPV52 (2.2\%). Although the overall proportion of women with unknown HIV status was high in this study, the prevalence of single and multiple HPV infections, as well as the proportion of HPV18, seemed higher among HIV-positive than among HIV-negative women [11].

\section{Cervical Cytologic Lesions in South Africa}

During 2009, a cross-sectional observational study was conducted among 1,010 HIV-seropositive women from Johannesburg using cytology-based Pap smears. Among 1,010 HIV-seropositive women, the prevalence of atypical glandular cells (AGC)/atypical squamous cells of undetermined significance (ASCUS), low grade squamous intraepithelial lesion (LSIL) and high grade squamous intraepithelial lesion (HSIL) or greater was 8.3, 23.5 and $18.0 \%$, respectively. The risk of cervical lesions was higher with $\mathrm{CD} 4<200$ cells $/ \mathrm{mm}^{3}$ versus CD4 levels $>500 / \mathrm{mm}^{3}$. HPV types $16(41.7 \%)$ and HPV 56 (22.2\%) were the most common types in women with a cytologic diagnosis of HSIL. Women with CD4 levels $<200 / \mathrm{mm}^{3}$ had a higher prevalence of HPV types 16 and 66. No statistical relationship between cervical lesions and HAART use was found. The burden of HPV infection and HSIL was high and correlated with HIV-induced immunosuppression. HPV 16 was the most common type in HSIL and increased in prevalence with greater immune suppression. It was concluded that prophylactic HPV 16 vaccination could prevent approximately $40 \%$ of HSIL cases [12].

\section{Cervical Cancer in South Africa}

Opportunistic cervical cancer screening has been available to all South African women for the last five decades. Data on the incidence of cervical cancer in South Africa prior to the establishment of the National Cancer Registry (NCR) in 1986 is scarce. However, in 1960, Higginson and Kettle published a survey of cancer incidence in black and colored people in the central- northern area of South Africa, from 1953 to 1955 [13]. Their data showed that cervical cancer was by far the most common cancer in women, accounting for $41.7 \%$ of all cancers in black women and $37 \%$ of all cancers in colored women. This data were based on all histological confirmed cases of invasive cervical cancer in the area and included rural and urban women.

South Africa launched a pathology-based national NCR in 1986, relying on information reported by private and public laboratories. The NCR records all cancers diagnosed by cytology, histology and haematology. According to the NCR, in 1986, the total number of cancers reported in women was 16 559, of which 2897 (17.4\%) were new cases of histologically or cytologically-confirmed cervical cancer [14]. In 1992, the total number of reported cancers in women increased to 25143 , but the percentage of new cases of cervical cancer remained at $17.8 \%$ (4 467). There were 1105 deaths $(24,74 \%)$ from cervical cancer recorded in 1992. In the 1993-1995 NCR report, an average of 3387 new cases of cancer of the cervix were reported per year, with 1 497 deaths reported for the year 1994. The Age-Standardized Incidence Rate (ASIR) of cervical cancer was 22/100 000. However, the ASIR was 27/100 000 for black women, the most disadvantaged women in SA in terms of access to health care [15]. A total of 6061 and 5203 new cases of cervical cancer were reported to the South African NCR in 1998 and 1999 respectively, representing $20 \%$ and $17 \%$ of all cancers in women during this two year period [16]. Statistics from the NRC for the years 2000 to 2011 are demonstrated in Table 1. Cervical carcinoma was the second most common cancer for females in the years 2002, 2004 to 2010, ranking just after breast carcinoma.

\begin{tabular}{|c|c|c|c|c|c|c|c|c|c|c|c|c|}
\hline & 2000 & 2001 & 2002 & 2003 & 2004 & 2005 & 2006 & 2007 & 2008 & 2009 & 2010 & 2011 \\
\hline Rank & $\begin{array}{c}3^{\text {rd }} \text { to } \\
\text { breast } \\
\text { and BCC }\end{array}$ & $\begin{array}{c}3^{\text {rd }} \text { to } \\
\text { breast } \\
\text { and } B C C\end{array}$ & $\begin{array}{l}2^{\text {nd }} \text { to } \\
\text { breast }\end{array}$ & $\begin{array}{c}3^{\text {rd }} \text { to } \\
\text { breast } \\
\text { and } B C C\end{array}$ & $\begin{array}{l}2^{\text {nd }} \text { to } \\
\text { breast }\end{array}$ & $\begin{array}{l}2^{\text {nd }} \text { to } \\
\text { breast }\end{array}$ & $\begin{array}{l}2^{\text {nd }} \text { to } \\
\text { breast }\end{array}$ & $\begin{array}{l}2^{\text {nd }} \text { to } \\
\text { breast }\end{array}$ & $\begin{array}{l}2^{\text {nd }} \text { to } \\
\text { breast }\end{array}$ & $\begin{array}{l}2^{\text {nd }} \text { to } \\
\text { breast }\end{array}$ & $\begin{array}{l}2^{\text {nd }} \text { to } \\
\text { breast }\end{array}$ & $\begin{array}{c}3^{\text {rd }} \text { to } \\
\text { breast } \\
\text { and BCC }\end{array}$ \\
\hline National Total females with cx carcinoma & 4680 & 4817 & 4796 & 4499 & 4636 & 4851 & 5071 & 4927 & 5178 & 5270 & 5433 & 4907 \\
\hline$\%$ of all cancers & 16.7 & 16.24 & 16.87 & 16.25 & 16.41 & 17.76 & 17.83 & 18.10 & 17.98 & 17.63 & 18.25 & 15.24 \\
\hline ASR & 20.23 & 25.53 & 24.80 & 22.74 & 24.40 & 22.56 & 24.72 & 21.78 & 22.38 & 20.44 & 22.33 & 21.67 \\
\hline Rank & First & First & First & First & First & First & First & First & First & First & First & First \\
\hline Total Black Females with cx carcinoma & 3693 & 3840 & 3792 & 3502 & 3468 & 3796 & 3958 & 3903 & 4040 & 4426 & 4401 & 4056 \\
\hline$\%$ of all cancers & 31.97 & 31.63 & 32,22 & 32.15 & 30.49 & 31.37 & 30.96 & 30.02 & 28.41 & 28.01 & 29.18 & 29.13 \\
\hline ASR & 30.16 & 30.56 & 29.50 & 26.72 & 28.43 & 27.38 & 29.46 & 25.86 & 26.23 & 21.63 & 26.05 & 25.49 \\
\hline Rank & $\begin{array}{c}3^{\text {rd }} \text { to } \\
\text { Breast } \\
\text { and BCC }\end{array}$ & $\begin{array}{c}3^{\text {rd }} \text { to } \\
\text { Breast } \\
\text { and BCC }\end{array}$ & $\begin{array}{c}3^{\text {rd }} \text { to } \\
\text { Breast } \\
\text { and BCC }\end{array}$ & $\begin{array}{c}3^{\text {rd }} \text { to } \\
\text { Breast } \\
\text { and BCC }\end{array}$ & $\begin{array}{c}3^{\text {rd }} \text { to } \\
\text { Breast } \\
\text { and BCC }\end{array}$ & $\begin{array}{c}3^{\text {rd }} \text { to } \\
\text { Breast } \\
\text { and BCC }\end{array}$ & $\begin{array}{l}2^{\text {nd }} \text { to } \\
\text { Breast }\end{array}$ & $\begin{array}{c}3^{\text {rd }} \text { to } \\
\text { Breast } \\
\text { and } B C C\end{array}$ & $\begin{array}{l}2^{\text {nd }} \text { to } \\
\text { Breast }\end{array}$ & $\begin{array}{c}3^{\text {rd }} \text { to } \\
\text { Breast } \\
\text { and BCC }\end{array}$ & $\begin{array}{c}3^{\text {rd }} \text { to } \\
\text { Breast } \\
\text { and BCC }\end{array}$ & $\begin{array}{c}3^{\text {rd }} \text { to } \\
\text { Breast } \\
\text { and BCC }\end{array}$ \\
\hline $\begin{array}{l}\text { Total colored Females with cervical } \\
\text { carcinoma }\end{array}$ & 413 & 375 & 348 & 330 & 393 & 378 & 385 & 309 & 373 & 391 & 366 & 359 \\
\hline$\%$ of all cancers & 13.14 & 10.89 & 11.45 & 10.83 & 12.18 & 12.22 & 12.43 & 10.70 & 12.30 & 12.11 & 12.27 & 9.55 \\
\hline ASR & 25.71 & 21.58 & 20.61 & 19.02 & 23.87 & 20.17 & 20.47 & 15.05 & 18.09 & 17.37 & 16.30 & 15.34 \\
\hline Rank & $6^{\text {th }}$ & $7^{\text {th }}$ & $7^{\text {th }}$ & $7^{\text {th }}$ & $7^{\text {th }}$ & $7^{\text {th }}$ & $7^{\text {th }}$ & $7^{\text {th }}$ & $6^{\text {th }}$ & $6^{\text {th }}$ & 5th & $5^{\text {th }}$ \\
\hline Total White females with cervical carcinoma & 342 & 352 & 389 & 382 & 387 & 372 & 380 & 344 & 372 & 353 & 411 & 437 \\
\hline$\%$ of all cancers & 2.96 & 2.93 & 3.34 & 3.28 & 3.52 & 3.72 & 3.77 & 3.92 & 4.20 & 3.71 & 4.24 & 3.17 \\
\hline ASR & 11.3 & 11.78 & 12.85 & 12.96 & 13.42 & 12.17 & 13.50 & 11.1 & 12.37 & 15.3 & 12.9 & 14.49 \\
\hline
\end{tabular}

Table 1: Statistics tabulated-National cancer registries 2000-2009 indicating national total, total black, colored and white females with cervical carcinoma 
Figure 1 demonstrates the difference in population totals of the various ethnic groups living in South Africa. Not only do African black females have the highest incidence rate of cervical carcinoma (Figure 2), they also form part of the ethnic group with the highest population total.

The age specific incidence of cervical carcinoma per 100000 females for the various ethnic groups is indicated in Figure 2. It confirms that the cervical cancer incidence rate for black females increases from ages 25-29 and peaks at 45-54 years of age. The incidence rate for white and colored females peaks at 40-49 years of age. Cervical carcinoma in the Asian population is minimal and the incidence rate of cervical carcinoma shows no significant age related incidence.

\section{HIV and Cervical Cancer}

South Africa has the largest expanding HIV burden in the world and it is estimated that 5.7 million South Africans are currently living with HIV/AIDS, of whom $60 \%$ are women [17]. HIV significantly increases the risk of persistent HPV infections, a risk factor in the development of cervical cancer. HIV-infected women have greater rates of pre-invasive and invasive cervical cancer rates whereas HPV infection promotes the acquisition of HIV [17]. Additionally, the development of cervical cancer is faster in HIV-positive women. In South Africa, HIV prevalence amongst young women compared to young men is at least 5-fold higher and young women in the age group 15 to 24 years remain the worst affected [17]. Many HIV-infected women are receiving antiretroviral therapy which has prolonged their lifespan. There are conflicting results as to whether antiretroviral therapy reduces the incidence of cervical cancer $[18,19]$. Thus prevention of cervical cancer is paramount.

In April 2011 the South African government launched the HIV Counseling and Testing (HCT) campaign, a new national drive to encourage people to know their HIV status and access counseling and treatment [20]. A universal HIV test and treat approach was implemented in South Africa in September 2016. It is hoped that this

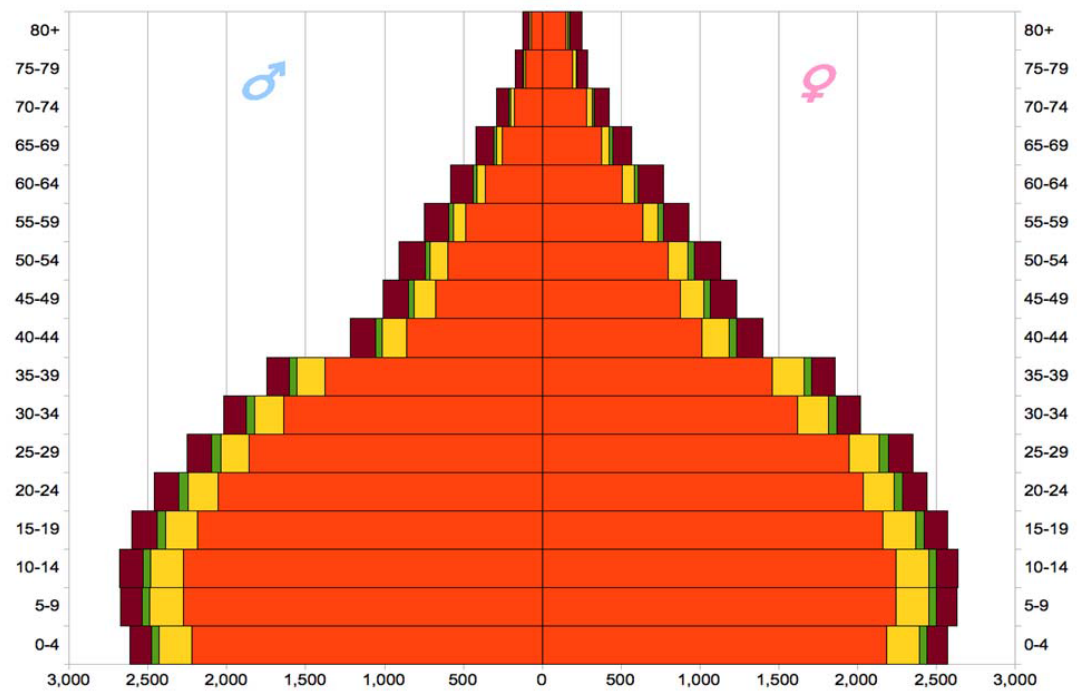

African/Black $\square$ Coloured $\square$ Indian/Asian $\square$ White

Figure 1: Population totals by age group as well as per ethnic group.

Age specific incidence of Cervical carcinoma

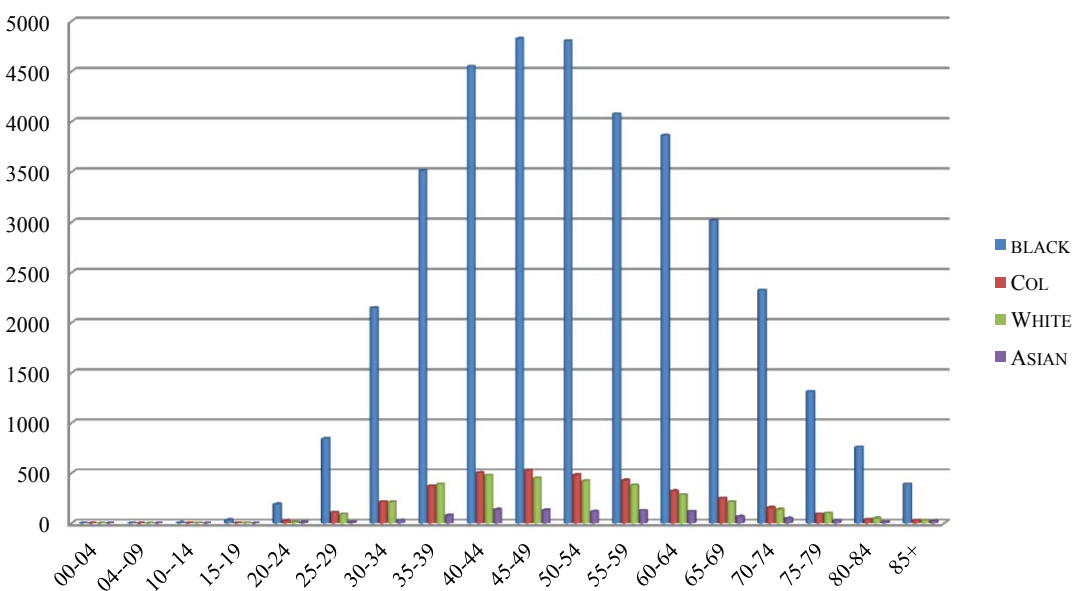

Figure 2: National cancer registries 2000-2011 indicating age specific incidence of cervical carcinoma in South Africa. 
initiative will all attendees at health facilities to test for HIV. All female patients are encouraged to have a Pap smear performed on testing positive for HIV.

\section{Cervical Cancer Prevention Strategies}

Numerous studies have proven the efficacy of a multipronged approach involving primary, secondary and tertiary prevention to curtail the incidence of, and mortality from cervical cancer $[9,21]$.

Primary prevention essentially includes healthy lifestyles, such as abstinence and safe sex and HPV vaccination. Secondary prevention of cervical cancer includes screening for precancerous lesions as well as early diagnosis followed by adequate treatment. The success of secondary prevention will be determined by the population coverage and the efficacy of the screening technique utilized. Current screening techniques in use in South Africa include mainly conventional cytology while most private laboratories (serving the private health care sector) offer liquid based cytology, as well as HPV testing (DNA or mRNA). Liquid based cytology and HPV testing are currently not available in the South African public health sector. VIA or VILI (visual inspection using acetic acid or Lugol's iodine) also forms part of secondary prevention. The current national cancer control policy does not endorse VIA or VILI, but non-governmental organizations (NGOs) are offering this service in various parts of the country. Tertiary prevention of cervical cancer involves the diagnosis and treatment of confirmed cases of cancer. Treatment is through surgery, radiotherapy and sometimes chemotherapy. Palliative care in the public sector is usually provided to patients when the disease has reached an incurable stage.

\section{Primary prevention}

Primary prevention essentially includes healthy lifestyles, such as abstinence and safe sex, cessation of smoking, and HPV vaccination [22]. Changing sex practices e.g. condom use would reduce the spread of both HIV and HPV but this is challenging to implement [14,22]. Spurgeon (1)In April 2014 the South African National Department of Health implemented a school-based HPV vaccination program for all girls 9 years and older, in grade 4 . The rollout included only public schools and targeted 450000 girls in 17807 public schools. Eligible girls were offered a two dose vaccination with Cervarix vaccine. The target was set at vaccinating $80 \%$ of grade 4 girls. Of the projected 17807 schools, 16495 schools were visited thus bringing the national coverage to $92.6 \%$ for the $1^{\text {st }}$ dose campaign. In the first round and second round of HPV vaccination in March-April and September-October 2014, 419589 and 329665 girls were vaccinated respectively while in 2015, 356228 received the first vaccine does while 329665 received both doses. Reasons for girls not receiving their vaccination included absenteeism when the vaccines were administered and lack of parental or guardian consent [23]. In 2015, 356228 and 329665 girls received their first and second vaccine doses, respectively.

\section{Source: Health information system National Department of Health SA}

Coverage for the total cohort of children born in 2004 (including boys and girls, and private schools) in SA is estimated at around 39\% [23]. The FDA approved a 9-valent vaccine, Gardasil $9^{\circ}$ in December 2014 [24]. Mathematical modeling predict that the addition of HPV types $31,33,45,52$ and 58 to the quadrivalent vaccine could potentially protect against $90 \%$ of all cervical cancers [24]. This vaccine is not currently available in South Africa. HPV vaccination of school girls prior to sexual debut should therefore have a significant impact on the incidence of, and mortality from, cervical cancer [25]. However, this reduction in invasive and pre-invasive cervical lesions will only be seen in the next 20-40 years as many non-vaccinated women have been and continue to be, exposed to HPV, some women will only be partially vaccinated and some women will be exposed to HR-HPV types not covered by current HPV vaccinations [26].

\section{Secondary prevention}

Secondary prevention aims to detect and treat preinvasive cervical lesions, before they become invasive. There are several secondary prevention modalities.

\section{Visual inspection}

In the vast majority of studies, visual inspection with acetic acid (VIA)/visual inspection with Lugol's iodine (VILI) demonstrates adequate sensitivity only if intensive quality assurance is undertaken. This may not always be possible in low middle income countries (LMIC). Visual inspection methods require minimal resources and are technologically accessible. Linking screening with VIA/VILI to treatment with cryotherapy may enable screening and treatment to take place in one visit, but this may result in women being subjected to unnecessary treatment. A number of studies have shown that cryotherapy is not associated with significant side effects or complications and is well tolerated; however, not all lesions are amenable to cryotherapy. Large loop excision of the transformation zone (LLETZ) is associated with complications, albeit few, but these do include adverse pregnancy outcomes. The National Department of Health in South Africa has not endorsed VIA in the current cervical cancer control policy. Nevertheless, various non-government associations (NGOs) have been doing VIA studies in some of the districts of the country. These studies have focused mainly on using visual inspection with acetic acid (VIA) and/or HPV DNA testing. Cross-sectional studies of VIA initially were quite reassuring and most studies demonstrated relatively high sensitivity, but low specificity and positive predictive value resulting in overtreatment. In longitudinal studies however, Denny et al. [27] in a randomized controlled trial of 6555 unscreened women aged 3565 years of age showed that the sensitivity of VIA for high-grade lesions was around $48 \%$ when women were followed up for 36 months. By contrast the sensitivity of HPV DNA testing for high-risk types (using Hybrid Capture 2) was consistently higher than either cytology or VIA and had a sensitivity of $86 \%$ for high-grade cervical cancer precursors over a 36 month follow-up period. Further, for every 100 women screened, the HPV screen-and-treat strategy eliminated 4.1 cases of CIN 2 or greater compared with VIA-and-treat, which eliminated 1.8 cases.

Firnhaber et al. [28] evaluated three cervical cancer screening methods to detect cervical intraepithelial neoplasia grade 2 and above (CIN 2+) in 1202 HIV-infected women in Johannesburg, South Africa; Pap smear, visual inspection with 5\% acetic acid (VIA) and human papillomavirus detection (HPV. Women were screened for cervical abnormalities with the Digene HC2 assay (HPV), Pap smear and VIA. Quality control was of utmost importance and very intense. VIA was performed by clinic nurses, digital photographs taken and then later reviewed by specialist physicians. VIA and HPV were positive in $45 \%$ and $61 \%$ of women respectively. Estimated sensitivity/specificity for HPV, Pap smear and VIA for CIN 2+ was $92 \% / 51.4 \%, 75.8 \% / 83.4 \%$ and 65.4/68.5\% (nurse reading), respectively. Although HPV was the most sensitive screening method for detecting CIN 2+, it was significantly less specific than conventional cytology and VIA with digital imaging review. Screening programs may need to be individualized in context of the resources and capacity in each area. 


\section{Cytology}

The National Department of Health approved the National Cancer Control Programme (NCCP) as a South African health policy in 1999 in order to address the cervical carcinoma burden. The National Guidelines for a Cervical Cancer Screening Program was launched in 2000. This policy indicated that every asymptomatic woman over the age of 30 should have 3 free Pap smears during her lifetime, with a 10 year interval between the Pap smears, should this patient remain asymptomatic. The goal of the national programme for Cervical Cancer Screening was to screen at least $70 \%$ of women nationally, within the target age group, within ten years of initiating the program. The shortage of health care workers; lack of equipment; loss to follow-up of patients with abnormal cytology and lack of ample awareness programmes include some of the reasons for the failure of this screening program. Due to a shortage of colposcopy and LLETZ facilities, many patients with an abnormal pap smear result are placed on very long waiting lists, some as long as 18 months [29]. It is important to note that sufficient screening coverage, as well as, treating screen positive women is required for a successful screening programme whatever screening modality is used.

\section{HPV testing}

While some private laboratories offer HPV testing, HPV testing is not yet freely available to the South African public sector as part of the national screening program. The new cervical cancer control policy soon to be signed in parliament addresses HPV testing to the public. HPV testing may be used as a primary screening tool as well as for triaging. Cost implications are being addressed.

The recognition of the strong causal relationship between persistent infection of the genital tract with high risk (HR) HPV types and the occurrence of cervical cancer has resulted in the development of a series of HPV DNA or RNA detection systems, many of which are commercially available. The advantages and disadvantages of these different diagnostic tests have been extensively studied [30]. Validated HPV testing is objective and lacks the inter-laboratory and interobserver variability of cervical cytology. HR-HPV testing is thus proposed as a possible primary cervical screening modality. Another application for HPV testing is to help better define the cytological category of ASCUS (atypical cells of undetermined significance).

High throughput assays suitable for large scale HR-HPV DNA testing are based on two different technologies:

1. hybridization-based assays, e.g. Hybrid Capture. This determines if HPV DNA is present or not, but does not inform what HPV type/s are present (Non-discriminatory HPV tests).

2. PCR-based technology e.g. Roche HPV test. This test will inform what HPV DNA types are present but is more costly than hybrid capture technology (Discriminatory HPV tests).

Variations on the above are systems that report if HR-HPV is present and specifically HPV types 16 and 18 , the most closely associated with invasive cervical cancer [31]. The $\mathrm{NDOH}$ is developing alternative treatment protocols for women with HPV types 16 and 18.

HPV tests detect HPV infection, rather than disease. The majority of women will clear this infection spontaneously within 2 years [32]. Persistent infection is a risk factor for cervical cancer. A vital step in the pathogenesis of cervical cancer is the integration of viral DNA into the host genome. HPV RNA is a better predictor of viral integration and hence disease rather than infection only.

\section{Future Perspectives}

Though cervical carcinoma is a largely preventable disease, an average of 4248 women in South Africa die annually from this disease [32]. Research shows that well- implemented, non-opportunistic national cervical screening programs can significantly reduce the morbidity and mortality rates attributed to cervical cancer [32].

According to the $\mathrm{WHO}$, successful screening programs require $>80 \%$ coverage, appropriate follow-up and management of patients with positive tests, effective links between screening diagnosis and treatment services, high quality care and adequate resources. This applies to all screening strategies viz. cytology, HPV and VIA/VILI. Currently, there is still no effective population-wide screening programme in South Africa. In several regions partial screening takes place and in the private sector opportunistic screening is commonly practised. A new cervical cancer control policy is due to be released soon, combining new technologies with current screening strategies.

Several cytologic modalities are available, as an alternative to conventional cervical smears being viewed by technologists under the microscope. Liquid based cytology (LBC) is a different method of preparing cytologic specimens for evaluation under the microscope. Although this technology has been available for the past 15-20 years, it has not been adopted by the public sector laboratory as it is costly. Some, but not all studies, have shown improved specimen adequacy and detection of abnormalities with LBC that may offset the cost. The public sector laboratory is planning to introduce LBC. Computer assisted screening of LBC smears should assist cytotechnologists with their workload.

Human papilloma virus (HPV) DNA/mRNA testing is the other new technology soon to be implemented in South African public health sector. Various algorithms will be available for HPV testing to be utilized as a primary test as well as for triaging. Co-testing has been discussed at length, but is currently too expensive to implement. The possible implementation of VIA/VILI in rural areas has also been discussed as a solution for the lost to follow-up of patients in these areas. Selfcollected samples (collected via brush or tampon) have also been part of pilot studies for HPV typing. HPV self-sampling may not be feasible in South Africa given the poor postal service. Many health care facilities lack a suitable private space where a woman can self-sample within a health care facility and, thus, it may be more advantageous for clinic personnel to screen a women instead [31]. This underscores the need to implement the tools already available for the prevention of cervical cancer, notably HPV vaccination, combined with well-organized national programmes for both screening and treatment.

\section{Ethics Approval and Consent to Participate}

This is a review article analyzing several, previously published studies. Therefore no ethics approval was sought.

\section{Author Contributions}

Suzette Jordaan analysed data and wrote the manuscript Pamela Michelow, Karin Richter and Cindy Simoens edited and reviewed the manuscript John-Paul Bogers edited, consolidated and reviewed the manuscript All authors reviewed and approved the manuscript.

\section{Acknowledgement}

National Health Laboratory Services for allowing me to access the data.

\section{Conflict of Interest}

The authors declare no conflict of interest. 
Citation: Jordaan S, Michelow P, Richter K, Simoens C, Bogers J (2016) A Review of Cervical Cancer in South Africa: Previous, Current and Future. Health Care Current Reviews 4: 180. doi: 10.4172/2375-4273.1000180

Page 6 of 6

\section{Funding}

University of Antwerp, Belgium

\section{References}

1. South African Human Papillomavirus and Related Cancers, Fact Sheet 2016

2. American Cancer Society (2015) Overview of the global cancer and tobacco burden and our global programs.

3. www.foxbusiness.com/industries/countries-that-spend-most-on-healthcare/\#ixzz1u87CIX2

4. Medical Research Council - Government of South Africa (1998) South African Demographic and Health Survey (SADHS).

5. Rees D, Murray J, Nelson G, Sonnenberg P (2010) Oscillating migration and the epidemics of silicosis, tuberculosis and HIV infection in South African gold miners. Am J Ind Med 53: 398-404.

6. Ebrahim S, Mndende XK, Kharsany, Mbulawa ZZA, Naranbhai, et al. (2016) High burden of human papillomavirus (HPV) infection among young women in KwaZulu-Natal, South Africa. PLoS ONE 11: e0146603.

7. Smith JS, Melendy A, Rana RK, Pimenta JM (2008) Age-specific prevalence of infection with human papillomavirus in females: A global review. J Adolescent Health 43.

8. Clifford GM, Franceschi S (2005) HPV in sub-Saharan Africa (editorial) Papillomavirus Rep 16: 322-326.

9. Richter K, Becker P, Horton A, Dreyer G (2013) Age-specific prevalence of cervical human papillomavirus infection and cytological abnormalities in women in Gauteng Province, South Africa. S Afr Med J 103: 313-317.

10. McDonald AC, Tergas AI, Kuhn L, Denny L, Wright TC Jr. (2014) Distribution of human papillomavirus genotypes among HIV-positive and HIV-negative women in Cape Town, South Africa. Front Oncol 4: 1-11.

11. Denny L, Adewole I, Anorlu R, Dreyer G, Moodley M, et al. (2014) Human papillomavirus prevalence and type distribution in invasive cervical cancer in sub-Saharan Africa. Int J Cancer 134: 1389-1398.

12. Shisana O, Rehle T, Simbayi LC, Zuma K, Jooste S, et al. (2014) South African National HIV prevalence, incidence and behavior survey, 2012. Cape Town, HSRC Press.

13. Higginson $\mathrm{J}$ and Oettle AG (1960) Cancer incidence in the Bantu and 'cape colored' races of South Africa: Report of a cancer survey in the Transvaal (1953-1955). J Natl Cancer Inst 24: 589-671.

14. National Cancer Registry Annual Report (1987).

15. Sitas F, Madhoo J, Wessie J (1998) Incidence of histologically diagnosed cancer in South Africa, 1993-1995, National Cancer Registry of South Africa. Johannesburg: South African Institute of Medical Research.

16. Omar T, Adler DH, Kakinami L, Modisenyane T, Tshabangu N, et al. (2012)
Increased regression and decreased incidence of human papillomavirusrelated cervical lesions among HIV-infected women on HAART. AIDS 26: 16451652.

17. Firnhaber C, Zungu K, Levin S, Michelow P, Montaner LJ, et al. (2009) Diverse and high prevalence of human papillomavirus associated with a significant high rate of cervical dysplasia in human immunodeficiency virus-infected women in Johannesburg, South Africa. Acta Cytol 53: 10-17.

18. www.gov.za/media-statements

19. Aggarwal P (2014) Cervical cancer: Can it be prevented. World J Clin Oncol 5: $775-780$.

20. Spurgeon D (1992) What do young black South Africans think about AIDS? IDRC Rep: 10-12.

21. Health Information System of National Department of Health.

22. U.S. Food and Drug Administration (2014) FDA approves Gardasil 9 for prevention of certain cancers caused by five additional types of HPV.

23. Richter KL, Dreyer G, Lindeque BG, Botha MH (2014) On behalf of the members of the South African HPV Advisory Board. HPV vaccine: Can we afford to hesitate? [correspondence]. South Afr Med J 104: 522-523.

24. Michelow P, Firnhaber C (2016) HPV vaccination in Southern Africa: A jab of hope in the fight against cervical cancer. Cancer 124: 695-698.

25. Denny L, Kuhn L, Hu CC, Tsai WY, Wright TC Jr. (2010) Human papillomavirusbased cervical cancer prevention: Long-term results of a randomized screening trial. J Natl Cancer Inst 102:1557-1567.

26. Firnhaber C, Van Le H, Pettifor A, Schulze D, Michelow P, et al. (2010) Association between cervical dysplasia and human papillomavirus in HIV seropositive women from Johannesburg South Africa. Cancer Causes Control 21: 433-443.

27. Blanckenberg N D (2013) Impact of the introduction of a colposcopy service in a rural South African sub-district on uptake of colposcopy. S Afr J OG 19: 81-85

28. Cox J, Castle PE, Behrens CM, Sharma A, Wright TC Jr, et al. (2013) Comparison of cervical cancer screening strategies incorporating different combinations of cytology, HPV testing and genotyping for HPV 16/18: results from the ATHENA HPV study. Am J Obstet Gynecol 208:184.e1-184.e11.

29. Richter K (2011) Understanding and incorporating HPV testing in cervical cancer screening: A south African perspective, pp: 9-14.

30. South African Human Papillomavirus and Related Cancers, Fact Sheet (2016)

31. Nowakowski A, Cybulski M, Śliwczyński A, Chil A, Teter Z, et al. (2015) The implementation of an organized cervical screening programme in Poland: An analysis of the adherence to European guidelines. BMC Cancer 15: 279.

32. Kamal EM, El Sayed GA, El Behery MM, El Shennawy GA (2014) HPV detection in a self-collected vaginal swab combined with VIA for cervical cancer screening with correlation to histologically confirmed CIN. Arch Gynecol Obstet 290: $1207-1213$ 